\title{
Whey Protein Concentrate as a Substitute for Non-fat Dry Milk in Yogurt
}

\author{
Berber $\mathbf{M}^{1}$, González-Quijano GK$^{2}$ and Alvarez VB ${ }^{1 *}$
}

${ }^{1}$ Department of Food Science, The Ohio State University, Columbus, OH 43210, USA

${ }^{2}$ Departamento de Graduados en Alimentos, Escuela Nacional de Ciencias Biológicas, Instituto Politécnico Nacional, Distrito Federal, México

\begin{abstract}
Whey is a liquid by-product produced during cheese manufacturing. Whey was once considered a waste product but it is converted to food ingredients through processing steps that include membrane filtration, heat or enzyme modification, and fractionation. These processes have made it possible to improve sweet whey utilization. Whey proteins have good nutritional properties and enhance the textural properties of food when they are used as ingredients. The objective of this study was to evaluate non-fat, low-fat and full-fat stirred style strawberry flavored yogurt formulated with whey protein concentrate 80 (WPC80) replacing non-fat dry milk (NFDM). Levels of total solid were adjusted to $14.8 \%, 15.7 \%$ and $17.3 \%$ for non-fat, low-fat and full-fat yogurts, respectively. Yogurts formulated with non-fat dry milk were used as controls for all fat levels. Batches of 17 pounds of yogurt at $0 \%$ fat, $1 \%$ and $3.25 \%$ fat were made by mixing milk with powdered ingredients in a liquefier and homogenized at 2,300 psi for first and 500 psi for second stage, respectively. Double stage homogenized yogurt milk was pasteurized at $92^{\circ} \mathrm{C}$ for 30 seconds. Following cooling, yogurts were fermented to a final $\mathrm{pH}$ of 4.5. Yogurts were analyzed for their chemical and physical properties following the standard methods of analysis. Sensory evaluation was done by descriptive method with hedonic and monadic scales by trained judges. Whey protein yogurts at all fat levels showed better water holding capacities (ca. 10\%) than controls with increased hardness (ca. 20\%) and viscosity (ca. 40\%). Sensory results revealed that whey protein yogurts had higher flavor and overall liking scores than controls, while controls had better scores for the yogurts' texture. Results showed that WPC 80 is a good alternative to replace NFDM completely in yogurt. Whey yogurts had equal or greater quality than yogurt products made with NFDM.
\end{abstract}

Keywords: Whey protein; Yogurt; Non-fat dry milk; WPC80

\section{Introduction}

Yogurt is a fermented milk product with a good reputation due to its probiotic cultures and its reported beneficial effects on health [1]. In theory, only milk and starter culture activity are needed to make a yogurt product. However, in practice, the total solids content of yogurt needs to be increased to prevent syneresis [2,3]. A preheating step at high temperatures is also needed to enhance gel formation by the whey proteins [4]. Yogurt can be fortified with milk protein powders to increase the total solids content to desired levels [5]. However, a study reported the importance of controlling the texture of cultured products when formulating the mix with lower milk solids and added stabilizers. The authors suggested that excessive use of stabilizer can negatively influence the sensory properties of the yogurt by producing an over stabilized texture and mouth-feel [6]. The common practice for yogurt manufacturing is to formulate yogurt with nonfat dry milk or whey protein concentrates, combined with heating to denature the whey proteins $[4,5]$. Caseins denature at $160^{\circ} \mathrm{C}$, however whey proteins start to denature above $70^{\circ} \mathrm{C}$ [7]. Since whey protein denaturation enhances the gel structure of yogurt, it will decrease the need for the addition of nonfat dry milk. Therefore, fortifying yogurt milk with whey protein powders may result in a better textured yogurt product [8].

Whey proteins are byproducts of the cheese making process and were once considered a waste product, but now are considered a valuable byproduct, due the properties and uses as mentioned in a review by Smithers [9]. Novel production techniques such as drying and membrane filtration allow a decrease in the lactose content while increasing protein content $[10,11]$. Whey protein structure is rich in branched chained amino acid (BCAA) such as leucine, valine, and isoleucine $[12,13]$. Whey proteins are available as acid whey, sweet whey, whey protein concentrate (protein content range $34 \%$ to $80 \%$ ) and whey protein isolate (protein content $>90 \%$ ) [13]. Whey proteins are also used as functional ingredients and as milk replacers in dairy products such as ice cream and as optional ingredient in yogurt products [14]. Since WPC is a dairy ingredient, which comes directly from milk, it can be used in dairy applications and labeled as a natural ingredient. Previous studies show that WPC addition to yogurt may improve texture and water holding [15]. Fortified yogurt with WPC to replace skim milk powder in the formulation resulted in a firmer coagulum, higher viscosity and less syneresis [16]. However, the U.S Code of Federal Regulations allows WPC to be used only as a secondary ingredient in yogurt applications [17]. Regulations state that the solids should come from either evaporated milk or non-fat dry milk (NFDM) to increase the non-fat milk solids level to the required $8.25 \%$. A recent study reported that variations in fat content and changing the casein-to-whey protein ration had a decreasing effect on flavor and increasing effect on graininess [18] Thus, the use of WPC as a major ingredient is limited [15]. The objective of this study is to investigate the replacement of NFDM with WPC in yogurt formulations at three fat levels. Products were analyzed for their compositional, textural and sensory properties.

\section{Whey protein yogurt}

Whey proteins were used to substitute non-fat dry milk in yogurt formulations at three fat levels; non-fat, low-fat and full-fat. Yogurt products were made at pilot plant scale following the commercial

*Corresonding author: Alvarez VB, Department of Food Science, The Ohio State University, Columbus, USA, Tel: 614-688-4961; Fax: 614-688-5459; E-mail: alvarez.23@osu.edu

Received October 12, 2015; Accepted November 03, 2015; Published November 18,2015

Citation: Berber M, González-Quijano GK, Alvarez VB (2015) Whey Protein Concentrate as a Substitute for Non-fat Dry Milk in Yogurt. J Food Process Technol 6: 530. doi:10.4172/2157-7110.1000530

Copyright: (C) 2015 Berber M, et al. This is an open-access article distributed under the terms of the Creative Commons Attribution License, which permits unrestricted use, distribution, and reproduction in any medium, provided the original author and source are credited. 
processing procedures. The finished products were tested for chemical, textural and sensory properties. The results shown that whey proteins were suitable to replace non-fat dry milk and produced high protein yogurts that were acceptable for the consumers.

\section{Materials and Methods}

\section{Formulation}

Control non-fat, low-fat and full fat products were produced with ingredient formulations similar to commercial products. Whey protein products were developed by replacing NFDM completely in control products with $80 \%$ whey protein concentrate. Control and whey protein product formulations and ingredients are presented in Table 1. Both control and whey protein products were formulated at the same total solids content for comparison purposes. The ingredients for yogurt formulation were the following: whey protein concentrate (WPC80, Agrimark, Lawrence, MA), yogurt stabilizer (Crest 41-1444, Crest Foods Inc., Ashton, IL), direct-vat-set yogurt culture (Streptococcus thermophilus, Lactobacillus bulgaricus, Lactobacillus acidophilus, and Bifidobacterium spp.) (Yo-Mix 205, Danisco, Madison, WI), strawberry base (FRD-12-25794, Fruitcrown Products Co., Farmingdale, NY), non-fat dry milk solids (NFDM) (Kroger, Cincinnati, OH) and sucrose (Kroger, Cincinnati, OH).

\section{Yogurt processing and pilot plant scale-up}

Raw milk (4\% milkfat), obtained from a dairy farm (The Ohio State University, Columbus, $\mathrm{OH}$ ) was used for yogurt processing. Milk was separated into skim milk $(<0.5 \%$ milkfat $)$ and cream $(20 \%$ milkfat $)$ using an Alfa-Laval 29AI separator (Stockholm, Sweden). Milk was kept at $4 \pm 2{ }^{\circ} \mathrm{C}$ at all times. Yogurt mixes were standardized at $0 \%$, $1 \%$ and $3.25 \%$ milkfat using the ingredients listed in Table 1 . Three 17 pound batches of yogurt were made for each fat level formulation. Each yogurt batch was homogenized at a pressure of 2,300 psi first stage and 500 psi second stage using a Lab $100 \mathrm{M}-\mathrm{G}$ two-stage valve homogenizer (Lubeck-Schlutut, Germany), and then pasteurized at $92^{\circ} \mathrm{C}$ for $30 \mathrm{sec}$ in an AVP Junior HTST system (Tonawanda, NY). Pasteurized yogurt mix was placed in a $4^{\circ} \mathrm{C}$ walk in refrigerated cooler for overnight storage. The next morning, each yogurt mix was placed into six separate 2.5 gallon 304 Stainless steel containers (Hamby Dairy supply, Maysville, MO) and warmed up to $42 \pm 1^{\circ} \mathrm{C}$ in a heated water bath (Fisher Scientific, Hampton, NH). Each yogurt batch was inoculated following the manufacturer's (Danisco Co. Inc., Madison, WI) recommended inoculation rate $(0.02 \% \mathrm{w} / \mathrm{w})$. Yo-Mix 205 starter culture (frozen pellets) was poured directly into the pasteurized mix. The mixture was agitated for 5 minutes to distribute the culture evenly. Temperature was maintained at $42 \pm 1^{\circ} \mathrm{C}$ during the fermentation process. The fermentation was stopped when the $\mathrm{pH}$ of the mixture reached 4.5 in about 4 to 4.5 hours. Strawberry base flavor (Fruitcrown, Farmingdale, NY) was added to the final yogurt at a rate of $15 \%(\mathrm{w} / \mathrm{w})$.
The finished product was placed into 8 ounce sanitized (200 ppm sodium hypochlorite) plastic containers, labeled and stored in the cooler at $4 \pm 2^{\circ} \mathrm{C}$ for 1 week.

\section{Chemical, textural and sensory analyses}

Chemical composition analyses: Yogurt samples were analyzed for moisture content using a CEM Lab Wave 9000 moisture/solids analyzer (Matthews, NC). Fat content was determined by the Babcock method (AOAC method number 989.04) [19]. Protein content was measured using a micro Kjeldahl total nitrogen (TN) analyzer (AOAC method number 991.20; 33.2.11) [19]. All analyses were conducted in triplicate.

pH: pH was measured using a pH meter WTW-pH 330 (Weilheim, Germany) with a glass electrode standardized at $25^{\circ} \mathrm{C}$ in the range 4.0 to 7.0 with commercial buffers (Fisher Scientific).

Hardness: An Instron 5542 series single column testing system (Norwood, MA) was used to measure yogurt hardness [20]. Samples were removed from refrigeration $\left(4 \pm 1^{\circ} \mathrm{C}\right)$ just before analysis. Gels were penetrated using a $35 \mathrm{~mm}$ diameter flat probe at a crosshead speed of $0.83 \mathrm{~mm} / \mathrm{s}$. Hardness $(\mathrm{N})$ was defined as the maximum mean force necessary to penetrate up to $50 \%$ compression of the gel's anvil height. Anvil height of yogurt samples was set at $(6.0 \mathrm{~cm})$, and anvil diameter was set at $(6.8 \mathrm{~cm})$.

Water holding capacity: A 20 g yogurt sample (Y) was centrifuged for $10 \mathrm{~min}$ at $1792 \mathrm{~g}$ at $4^{\circ} \mathrm{C}$. The whey expelled (W) was removed and weighed, and water holding capacity was calculated by the method of Sodini [21].

Viscosity: Apparent viscosity was measured using a viscometer (Brookfield DV-II+, Middleboro, MA) with an LV spindle number 3 rotated at $1.5 \mathrm{rpm}$. Samples were kept in a water bath at $23^{\circ} \mathrm{C}[22]$.

Sensory analysis: The sensory panel consisted of 5 expert members who had previous experience in sensory evaluation of yogurts. Products were presented in 3-digit coded, white plastic isothermal cups stored at $4^{\circ} \mathrm{C}$. The samples were at approximately $10^{\circ} \mathrm{C}$ when they were tested according to the procedure of Tribby [22]. Panelists were provided with mineral water for palate cleansing between samples. The sessions were carried out in a temperature controlled room at $20^{\circ} \mathrm{C}$ under white lighting in individual booths. Data acquisition was assisted by CompuSense Five software (CompuSense Inc., 2010). Both monadic and hedonic scales were used to rate the flavor and the texture attributes of products. The attributes were evaluated in the following order: visual texture with a spoon, odor, aroma, taste, and texture-in-mouth.

Experimental design: The experimental design was a randomized complete block, performed in triplicate on separate days (runs), with run as the blocking variable. Variables were the fat content and the day effect for homogenous results. All analyses were performed in

\begin{tabular}{|c|c|c|c|c|c|c|}
\hline Ingredients(\%)/Products & $\begin{array}{l}\text { Control } \\
\text { Non-fat }\end{array}$ & $\begin{array}{l}\text { Control } \\
\text { Low-fat }\end{array}$ & $\begin{array}{l}\text { Control } \\
\text { Full-fat }\end{array}$ & $\begin{array}{l}\text { Whey } \\
\text { Non-fat }\end{array}$ & $\begin{array}{l}\text { Whey } \\
\text { Low-fat }\end{array}$ & $\begin{array}{l}\text { Whey } \\
\text { Full-fat }\end{array}$ \\
\hline Cream & - & 4.8 & 15 & - & 4.3 & 14.5 \\
\hline Skim milk & 79.25 & 74.45 & 64.25 & 79.25 & 74.95 & 64.75 \\
\hline WPC80 & - & - & - & 2 & 2 & 2 \\
\hline NFDM & 2 & 2 & 2 & - & - & - \\
\hline Sugar & 3 & 3 & 3 & 3 & 3 & 3 \\
\hline Stabilizer & 0.75 & 0.75 & 0.75 & 0.75 & 0.75 & 0.75 \\
\hline Flavor (strawberry) & 15 & 15 & 15 & 15 & 15 & 15 \\
\hline Total $(\%)$ & 100 & 100 & 100 & 100 & 100 & 100 \\
\hline
\end{tabular}

Table 1: Formulations for the developed control and whey protein products. 
triplicate and were analyzed by one way ANOVA with sample formula for yogurt and run as the main effects, using PASW (formerly known as SPSS) statistical software (Release 18.0.2). Means comparisons were made when the effect was significant $(\mathrm{P}<0.05)$ using Tukey's HSD procedure. All results were reported as the combined means of 3 repeated measures from each of the 3 runs made.

\section{Results and Discussion}

\section{Composition}

Total solids include fat, protein, carbohydrate and minerals for the yogurt product. Total solids content was similar in control and whey yogurts with the same levels of fat but it was significantly different $(P<0.05)$ among products with different levels of fat (Table 2$)$. Nonfat control and non-fat whey protein yogurts had the same total solids content of $14.8 \%$. Low-fat and full-fat yogurts showed the same levels of total solids content, in both control and $80 \%$ WPC containing samples, $15.7 \%$ and $17.3 \%$, respectively. The effect of total solids on the properties of yogurt will be discussed later in the corresponding sections. The code of federal regulations [17] require that yogurt products should have levels of $0 \%$ to $0.5 \%, 0.5 \%$ to $2 \%$ and more than $3.25 \%$ in order to be named as non-fat, low-fat and full-fat, respectively. Low-fat control and whey protein yogurts had around $1.1 \%$ fat content (Table 2) while full-fat had $3.25 \%$ fat content. There were no differences $(P<0.05)$ in fat content between control and whey samples of both lowfat and full-fat yogurts. However, non-fat whey yogurt had $0.1 \%$ fat content while control non-fat yogurt had no detectable fat content. The reason for this difference in the fat content may be attributed to the WPC used in the formulation, which contains around $5-8 \%$ of fat. The presence of fat is important to both texture and flavor of yogurt. Nonfat yogurts had lower texture and sensory results than low-fat and full fat yogurts. Other studies such as Sandoval-Castilla, et al. [20] reported similar observations related to texture and flavor of yogurt, which were enhanced by homogenization of fat globules. In addition to the presence of fat, the interactions of fat globules with protein molecules are important for the textural properties of the finished product $[2,23]$. Higher sensory and texture scores of control low-fat yogurt (1.1\% fat content) can be explained by this interaction [2]. Because control lowfat yogurt was fortified with casein and double stage homogenized at $2300 \mathrm{psi}$ and $500 \mathrm{psi}$, this would result in more reformed casein micelles. Protein is the one of main solid ingredients in the yogurt products. The protein content was significantly different $(P<0.05)$ among all control and whey yogurts (Table 2). Control non-fat yogurt had $3.68 \%$ protein content and non-fat whey yogurt had the highest protein content of $4.61 \%$. This was due to the high protein content of WPC (80\%). Likewise, the reason for the low protein content for the control yogurts was the protein source, which is NFDM (34\%). Similar results were observed for low-fat and full-fat control and whey containing

\begin{tabular}{|c|c|c|c|}
\hline & Total solids (\%) & Fat content (\%) & Protein content (\%) \\
\hline Control non-fat & $14.8 \mathrm{c}$ & ND$^{*}$ & $3.68 \mathrm{~d}$ \\
\hline Whey non-fat & $14.8 \mathrm{c}$ & $0.1 \mathrm{c}$ & $4.61 \mathrm{a}$ \\
\hline Control low fat & $15.7 \mathrm{~b}$ & $1.1 \mathrm{~b}$ & $3.59 \mathrm{e}$ \\
\hline Whey low-fat & $15.7 \mathrm{~b}$ & $1.1 \mathrm{~b}$ & $4.55 \mathrm{~b}$ \\
\hline Control full-fat & $17.3 \mathrm{a}$ & $3.3 \mathrm{a}$ & $3.45 \mathrm{f}$ \\
\hline Whey full-fat & $17.3 \mathrm{a}$ & $3.3 \mathrm{a}$ & $4.39 \mathrm{c}$ \\
\hline
\end{tabular}

*ND: not detectable

a-f Different letter among the bars indicates significant difference $(P<0.05)$ (Tukey's test).

* Results are mean of triplicate analyses of three different batches.

Table 2: Total solids, fat and protein content of control and whey yogurts.

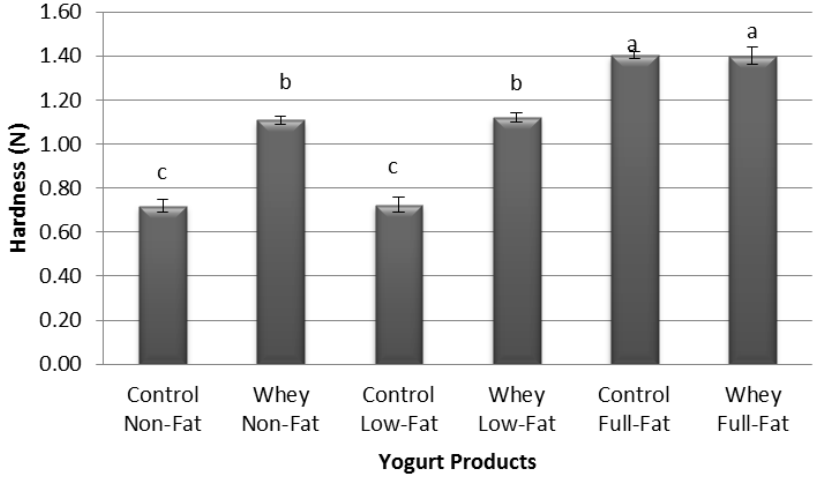

Figure 1: Hardness values of yogurt products.

a-d Different letter among the bars indicates significant difference $(P<0.05)$ (Tukey's test).

${ }^{\star}$ Results are mean of triplicate analyses of three different batches.

yogurt products. This suggests that high protein concentration in the added $80 \%$ WPC was the reason for whey protein yogurts to have higher protein content than control yogurts. The presence of protein is essential for good body and texture of yogurt products Sodini, et al. [21]. Whey low-fat yogurts had $4.55 \%$ protein content while control low-fat yogurts had $3.59 \%$. The main reason for the addition of non-fat milk solids in yogurt formulations is to add milk protein. Increased levels of protein resulted in higher values in hardness, WHC and viscosity scores for whey protein yogurts versus controls. Henriques, et al. [3], as well as Bong and Moraru [5] also reported that increased protein content improved the textural properties of yogurt products; these findings may explain the higher texture results for whey protein yogurts (Figure 1) due to the high protein content in the formulation.

Heat induced protein denaturation is a treatment that affects texture, flavor and chemical properties of yogurt products [24]. Improved texture of $80 \%$ WPC containing yogurt could have been the result of the denaturation of whey proteins. However, increased protein content combined with protein denaturation in whey protein yogurts might be the reason for their lower texture sensory evaluation scores compared to the controls. Full-fat whey yogurt had $4.39 \%$ protein content while full-fat control yogurt had $3.45 \%$. The variation was significantly different $(P<0.05)$, and full-fat yogurts had the lowest protein content when compared to non-fat and low-fat yogurts, due to the fact that they contained the highest fat content of about $3.25 \%$.

When comparing the $\mathrm{pH}$ results among yogurt products at the same fat level, the variations for $\mathrm{pH}$ were significantly different $(\mathrm{P}<$ $0.05)$ for all non-fat, low-fat and full-fat control whey protein yogurts (Figure 2). The differences in flavor perception are shown in (Figure 3). An important factor for these differences could be the $\mathrm{pH}$, which results from acid formation during fermentation that is necessary to coagulate proteins to form the typical coagulum of yogurt. The acid level present gives the acid taste of yogurt. Soukoulis, et al. [25] reported that $\mathrm{pH}$ affected the flavor of yogurt when WPC were added in the formulation. Furthermore, other authors found that higher whey protein content in yogurts increased the buffering capacity in the product and also influenced the flavor perception $[24,26,27]$.

Control full-fat yogurt had a $\mathrm{pH}$ of 4.39 while whey full-fat yogurt had a $\mathrm{pH}$ of 4.37. As in the case of the low-fat yogurt results, the $\mathrm{pH}$ of full fat products decreased as fat content increased. Low $\mathrm{pH}$ is reported to cause textural defects in yogurt products since it decreases the gel 


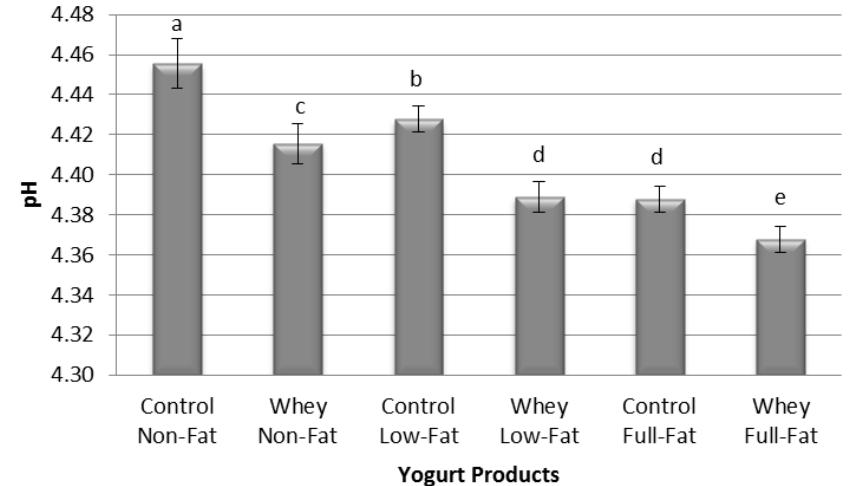

Figure 2: $\mathrm{pH}$ of yogurt products.

${ }^{a-e}$ Different letter among the bars indicates significant difference $(P<0.05)$ (Tukey's test).

${ }^{*}$ Results are mean of triplicate analyses of three different batches.

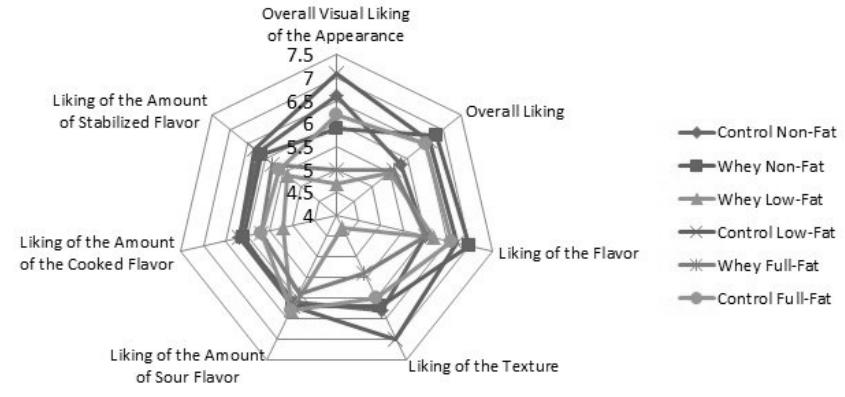

Figure 3: Hedonic scale sensory scores of yogurt products.

${ }^{*}$ Results are mean of triplicate analyses of three different batches

strength due to excessive charge repulsion [27].

\section{Texture}

Hardness was used to measure the textural properties of yogurt products, in this case, hardness values of non-fat, low-fat and fullfat whey protein yogurt samples at non-fat, low-fat and full-fat were significantly different $(P<0.05)$ than the controls (Figure 1). Control non-fat and low-fat yogurts had the same lowest hardness values of $0.72 \mathrm{~N}$ each while whey non-fat and whey low-fat yogurts had values of $1.11 \mathrm{~N}$ and $1.12 \mathrm{~N}$, respectively. The increased difference in hardness between control and whey protein yogurts may been associated with the denaturation of whey proteins.

These observations are supported by the results of a study reporting that yogurt containing whey proteins had firmer texture than casein fortified yogurt [28]. A similar effect was observed in control full-fat yogurt that had a hardness value of $1.40 \mathrm{~N}$, which was lower than 1.47 $\mathrm{N}$ for whey full-fat yogurt. Increased levels of fat content produced greater increase in the hardness value of both control $(1.40 \mathrm{~N})$ and whey protein yogurt $(1.47 \mathrm{~N})$. Other studies reported similar results and concluded that the increase in yogurt hardness was directly related to fat and total solids content [6]. As indicated earlier, total solids content also influenced the hardness of both control and whey protein yogurts. Non-fat and low-fat yogurts had $14.8 \%$ and $15.7 \%$ total solids content and their respective hardness values were $0.72 \mathrm{~N}$ and 1.12 $\mathrm{N}$. These total solids values are lower than those for full-fat product that had $17.3 \%$ total solids and $1.47 \mathrm{~N}$. The optimum total solids level was in the range of 14 to $16 \%$ to produce acceptable products; some studies reported results where total solids content affects the textural properties of yogurt products [6]. WHC is an indicator of how much water can be held in a yogurt product. Control non-fat yogurt had the lowest water holding capacity at $582 \mathrm{gm} / \mathrm{kg}$ while whey full-fat had the highest water holding capacity of $768 \mathrm{gm} / \mathrm{kg}$ (Figure 4). There are many factors associated with yogurt's water holding capacity. Total solids content, protein and fat content, source of protein, selection of starter culture (either ropy or non-ropy) and processing conditions are important factors that decrease or increase the water holding capacity in yogurts [24]. Non-fat whey yogurt had higher a WHC score of 682 $\mathrm{gm} / \mathrm{kg}$ than control non-fat, which had a value of $582 \mathrm{gm} / \mathrm{kg}$ Since both products have the same fat and total solids content, the higher WHC can be attributed to addition of whey proteins. Sodini, et al. [24] reported that protein denaturation was responsible for the increase of water holding capacity in yogurt products. Similar studies also stated that whey protein denaturation enhanced the gelling properties and hence the WHC with adequate heat treatment [29].

Whey low-fat yogurt had a higher water holding capacity of 730 $\mathrm{gm} / \mathrm{kg}$ than control low-fat, which had $622 \mathrm{gm} / \mathrm{kg}$ Similarly, the water holding capacity score of $768 \mathrm{gm} / \mathrm{kg}$ for whey full-fat yogurt was higher than the control full-fat yogurt, which had a WHC score of $725 \mathrm{gm} / \mathrm{kg}$. Increase in total solids and fat content resulted in an increase of water holding capacity for all yogurt products. Some studies also concluded that the origin and total solids content affect the water holding capacity of yogurt products as well the viscosity [30]. An additional factor that influences the WHC of yogurt is the homogenization of the mix during yogurt making. Homogenization increases the interaction of protein molecules with fat globules and free water in the yogurt mix prior to coagulation [8]. The viscosity values of all yogurts increased with increased fat content (Figure 5). Control non-fat yogurt had the lowest viscosity score while whey full-fat yogurt had the highest viscosity score. Whey proteins also increased viscosity of yogurts at all fat levels. Control non-fat yogurt had a viscosity score of 19,355 cPs that was lower than the $31,847 \mathrm{cPs}$ value for non-fat whey yogurts. Similar results were observed in low-fat yogurt products. Control lowfat yogurt had 21,340 cPs while whey low-fat yogurt had 33,011 cPs.

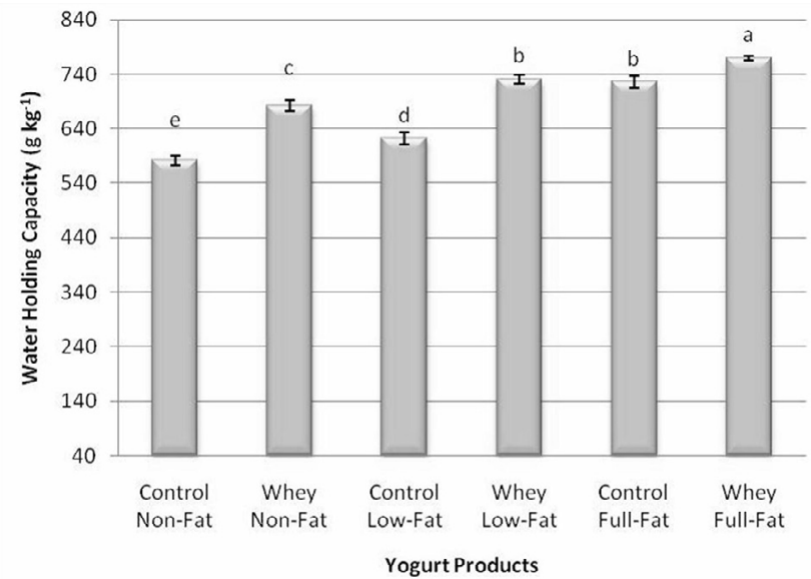

Figure 4: Water holding capacity of yogurt products.

a-e Different letter among the bars indicates significant difference $(P<0.05)$ (Tukey's test).

${ }^{*}$ Results are mean of triplicate analyses of three different batches. 


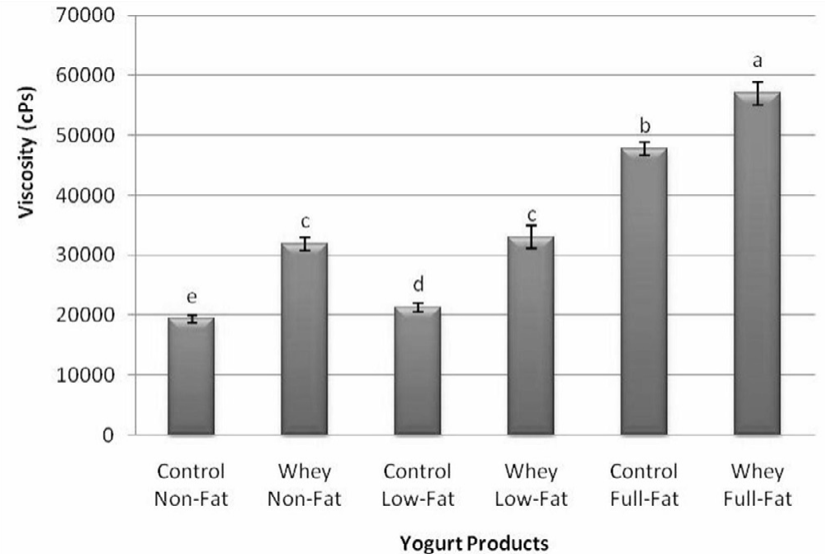

Figure 5: Viscosity values of yogurt products.

${ }^{a-e}$ Different letter among the bars indicates significant difference $(P<0.05)$

(Tukey's test)

${ }^{*}$ Results are mean of triplicate analyses of three different batches.

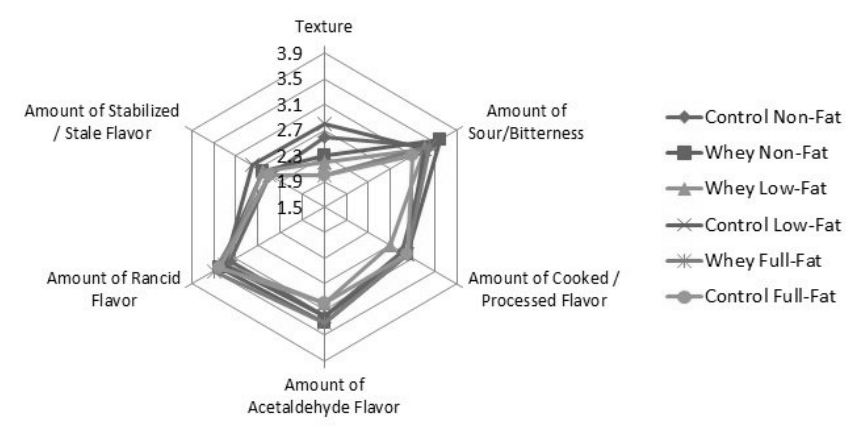

Figure 6: Monadic scale sensory scores of yogurt products.

${ }^{*}$ Results are mean of triplicate analyses of three different batches.

These viscosity results may be due to the high total solids content and whey protein denaturation of the yogurt mix. Isleten and KaragulYuceer [23] reported the addition of whey protein isolate to increase total solids resulted in the increase in viscosity of yogurts. Whey full-fat yogurt had the highest viscosity score of $56,977 \mathrm{cPs}$ when compared with the control full-fat score of $47,722 \mathrm{cPs}$. The increase in viscosity was significantly different $(P<0.05)$ from low-fat and non-fat yogurts. Brauss et al. [31], Soukoulis, et al. [25], and others, noticed that the heat treatment also affects the viscosity, as well as the fat and protein content.

\section{Sensory}

Sensory results on a monadic scale (1: low amount to 5: excess amount) showed differences between products (Figure 6). Another name for the monadic scale is the metric scale and it is used for noncomparative measurements. Texture scores had the most variations among whey yogurts. Control low-fat yogurt had the most desirable texture score of 2.8 compared to other yogurts.

Whey low-fat and control full-fat products had the best scores for acetaldehyde flavor with a score of 3.0. Acetaldehyde is the major flavor compound of the fermentation process in yogurt applications and gives yogurt its famous tarty flavor [32]. González-Martínez, et al. [15] reported more production of acetaldehyde in yogurt with whey protein powder used to fortify the yoghurt mix at levels ranging between 0.6 and $4 \%$. In our case whey protein is the main added solid, so the change in formation of acetaldehyde during the fermentation process may be due to the interactions between the nutrients and the starter cultures [33]. Also the whey proteins $\beta$-lactoglobulin ( $\beta-\mathrm{LG}$ ) and $\alpha$-lactalbumin $(\alpha-\mathrm{LB})$ interacted differently with fat content as observed in previous work by Corredig and Dalgleish [34]. They found that both $\alpha-L B$ and $\beta$-LG were bound to the surfaces of fat globules when milk was heated in the temperature range $65-85^{\circ} \mathrm{C}$. For sour/bitter scores, control and whey protein products scored between 3.1 and 3.6. The results showed that the acidity of yogurts was well developed. The $\mathrm{pH}$ of yogurts was also in agreement with the sour results since they ranged between $\mathrm{pH}$ 4.36 and 4.46 .

The most widely used measuring scale for food acceptability is the 9-point hedonic scale. This scale starts with dislike extremely (scale 1) and ends with like extremely (scale 9 ). Whey protein non-fat product had the highest overall likeability score of 6.8 compared to other yogurts followed by control low-fat (6.6) and control non-fat yogurt (6.5) (Figure 3). These scores suggest that $80 \%$ WPC may work well as an added ingredient in low fat yogurt, especially when today's low fat and high protein diets are taken into account. For overall visual likeability appearance, whey protein products had lower scores than the control yogurts. Control low-fat yogurt had the highest score of 7.1 in this category which was in agreement with the monadic texture score; it may also be associated with the texture liking. Control lowfat had the highest texture liking score at (7.0) followed by control non-fat (6.3) and whey non-fat (6.2) respectively. Whey low-fat and full-fat yogurts had the lowest scores of 4.3 and 6.0, respectively. This result indicates that textural issues might be related to whey protein denaturation which caused more firm gel formation of yogurt. Nonfat whey yogurt had highest score of 7.0 in the flavor liking category followed by control low-fat (6.7) and control full-fat (6.6). This result may be related to the volatile high acetaldehyde composition of non-fat whey yogurts. Liking scores of the stabilized, cooked and sour flavor were not different $(P<0.05)$. Sensory scores revealed that control lowfat yogurt had better textural properties than others, while non-fat whey yogurt had higher scores than others for the flavor.

\section{Conclusion}

The results of this study have shown that it is possible to completely replace NFDM in yogurt formulations with $80 \%$ WPC while enhancing textural properties such as water holding, hardness and viscosity. Also, fat was shown to increase water holding, hardness and viscosity. Additionally, whey protein addition improved the protein content and reduced syneresis. Yogurt can be made with $80 \%$ whey protein concentrate as added solids without compromising the overall acceptability. Readers should be aware that the effect of WPC on yogurt properties depends on the type and hence manufacturing conditions of the WPC. In this study only one type WPC was used and the results may not be representative of all commercial WPCs.

\section{Acknowledgments}

The author Murat Berber gratefully acknowledges the support given by the Ministry of National Education (Turkey) for scholarship. Additionally, the authors Murat Berber and Valente B. Alvarez want to thank the support of The Ohio State University Wilbur A. Gould Food Industries Center. The author Génesis K. González-Quijano wants to acknowledge the support given by CONACyT and the Escuela Nacional de Ciencias Biológicas, IPN-México.

\section{References}

1. Wang $H$, Livingston KA, Fox CS, Meigs JB, Jacques PF, et al. (2013) Yogurt 
Citation: Berber M, González-Quijano GK, Alvarez VB (2015) Whey Protein Concentrate as a Substitute for Non-fat Dry Milk in Yogurt. J Food Process Technol 6: 530. doi:10.4172/2157-7110.1000530

Page 6 of 6

consumption is associated with better diet quality and metabolic profile in American men and women. Nutr Res 33: 18-26.

2. Aziznia S, Khosrowshahi A, Madadlou A, Rahimi J, Abbasi H, et al. (2009) Texture of nonfat yoghurt as influenced by whey protein concentrate and Gum Tragacanth as fat replacers. Int J Dairy Technol 62: 405-410.

3. Henriques MF, Gomes DGS, Pereira CD, Gil MM (2013) Effects of liquid whey protein concentrate on functional and sensorial properties of set yogurts and fresh cheese. Food Bioprocess Tech 6: 952-963.

4. Xu ZM, Emmanouelidou DG, Raphaelides SN, Antoniou KD (2008) Effects of heating temperature and fat content on the structure development of set yogurt. J Food Eng 85: 590-597.

5. Bong DD, Moraru Cl (2014) Use of micellar casein concentrate for Greek-style yogurt manufacturing: Effects on processing and product properties. J Dairy Science $97 \cdot 1259-1269$

6. Lucey JA (2004) Cultured dairy products: An overview of their gelation and texture properties. Int J Dairy Technol 57: 77-84.

7. Dissanayake M, Ramchandran L, Piyadasa C, Vasiljevic T (2013) Influence of heat and $\mathrm{pH}$ on structure and conformation of whey proteins. Int Dairy Journal 28: $56-61$.

8. Loveday SM, Sarkar A, Singh H (2013) Innovative yoghurts: Novel processing technologies for improving acid milk gel texture. Trends Food Sci Tech 33 5-20.

9. Smithers GW (2008) Whey and whey proteins-From 'gutter-to-gold'. Int Dairy Journal 18: 695-704.

10. Hausmann A, Sanciolo P, Vasiljevic T, Kulozik U, Duke M, et al. (2014) Performance assessment of membrane distillation for skim milk and whey processing. J Dairy Science 97: 56-71.

11. Espina V, Jaffrin MY, Frappart M, Ding LH (2010) Separation of casein from whey proteins by dynamic filtration. Desalination 250: 1109-1112.

12. Wit JN (1998) Nutritional and functional characteristics of whey proteins in food products. J Dairy Sci 81: 597-608.

13. Ha E, Zemel MB (2003) Functional properties of whey, whey components, and essential amino acids: mechanisms underlying health benefits for active people (review). J Nutr Biochem 14: 251-258.

14. Gauche C, Tomazi T, Barreto PLM, Ogliari PJ, Bordignon-Luiz MT, et al (2009) Physical properties of yoghurt manufactured with milk whey and transglutaminase. LWT- Food Sci Technol 42: 239-243.

15. González-Martínez C, Becerra M, Cháfer M, Albors A, Carot JM, et al. (2002) Influence of substituting milk powder for whey powder on yoghurt quality. Trends Food Sci Tech 13: 334-340.

16. Guirguis N, Broome MC, Hickey M (1984) The effect of partial replacement of skim milk powder with whey-protein concentrate on the viscosity and syneresis of yogurt. Aust J Dairy Technol 39: 33-35.

17. Code of Federal Regulations (CFR) (2013) Tittle 21. Food and Drugs.

18. Tomaschunas M, Hinrichs J, Kohn E, Busch-Stockfisch M (2012) Effect of casei-to-whey protein ratio, fat content and protein content on sensory properties of stirred yoghurt. Int. Dairy Journal 26: 31-35.

19. Association of Official Analytical Chemists (AOAC) (2002) Official methods of analysis. Arlington, VA, USA

20. Sandoval CO, Lobato CC, Aguirre ME, Vernon CEJ (2004) Microstructure and texture of yogurt as influenced by fat replacers. Int. Dairy Journal 14: 151-159.

21. Sodini I, Montella J, Tong PS (2005) Physical properties of yogurt fortified with various commercial whey protein concentrates. J. Sci. Food Agric 85: 853-859.

22. Tribby D (2009) The Sensory Analysis of Dairy Products: Yogurt. (2nd edn) Springer Science, New York.

23. Isleten M, Karagul-Yuceer $Y$ (2006) Effects of dried dairy ingredients on physical and sensory properties of nonfat yogurt. J Dairy Sci 89: 2865-2872.

24. Sodini I, Mattas J, Tong PS (2006) Influence of pH and heat treatment of whey on the functional properties of whey protein concentrates in yoghurt. Int Dairy Journal 16: $1464-1469$.

25. Soukoulis C, Panagiotidis P, Koureli R, Tzia C (2007) Industrial yogurt manufacture: Monitoring of fermentation process and improvement of final product quality. J Dairy Sci 90: 2641-2654.

26. Kelly M, Vardhanabhuti B, Luck P, Drake MA, Osborne J, et al. (2010) Role of protein concentration and protein-saliva interactions in the astringency of whey proteins at low pH. J Dairy Sci 93: 1900-1909.

27. Vardhanabhuti B, Kelly MA, Luck PJ, Drake MA, Foegeding EA, et al. (2010) Roles of charge interactions on astringency of whey proteins at low $\mathrm{pH}$. J Dairy Sci 93: 1890-1899.

28. Guggisberg D, Eberhard P, Albrecht B (2007) Rheological characterization of set yoghurt produced with additives of native whey proteins. Int. Dairy Journal 17: $1353-1359$.

29. Mao R, Tang J, Swanson BG (2001) Water holding capacity and microstructure of gellan gels. Carbohyd. Polym 46: 365-371.

30. And JL, Guo M (2006) Effects of polymerized whey proteins on consistency and water-holding properties of goat's milk yogurt. J. Food Sci 71: 34-38.

31. Brauss MS, Linforth RST, Cayeux I, Harvey B, Taylor AJ, et al. (1999) Altering the fat content affects flavor release in a model yogurt system. J. Agric. Food Chem 47: 2055-2059.

32. Antunes AEC, Cazetto TF, Bolini HMA (2005) Viability of probiotic microorganisms during storage, postacidification and sensory analysis of fat-free yogurts with added whey protein concentrate. Int J Dairy Technol 58: 169-173.

33. Zisu B, Shah NP (2003) Effects of pH, Temperature, supplementation with whey protein concentrate, and sdjunct cultures on the production of exopolysaccharides by Streptococcus thermophilus 1275. J Dairy Sci 86: 34053415.

34. Corredig M, Dalgleish DG (1996) Effect of different heat treatments on the strong binding interactions between whey proteins and milk fat globules in whole milk. J Dairy Res 63: 441-449. 